УДК 641.53.094: 637.5.034

DOI

\title{
МОДЕЛЬ ПРОЦЕСУ ТЕПЛОМАСОПЕРЕНОСУ ПРИ КОНВЕКТИВНОМУ СУШІННІ М'ЯСНИХ ВИРОБІВ
}

Ощипок І. М. д-р техн. наук, професор

Львівський торговельно-економічний університет, м. Львів

\begin{abstract}
Анотація. У статті розглянута модель. розв'язання актуального завдання у сфері техніки й технологіi сушіння м'ясних виробів, яка пов 'язана з факторами вивчення і поглиблення уяви про фізичну сутність $i$ закономірність переносу енергї й речовини при різних методах сушіння для створення науково обтрунтованої методики техніко-економічної оцінки сушильних установок при сушінні м'ясних виробів. Питання математичного моделювання прочесу сушіння поверхневої вологи з виробів після відповідної технологічної обробки є актуальним, і визначає терміни тривалого зберігання. Задача випаровування рідини з поверхні капілярнопористого тіла розглянута в трьох аспектах, а загальна задача моделювання процесів тепломасопереносу при конвективному сушінні м'ясних продуктів з додатковим підведенням ІЧ енергії, розглянута у двох складових. Перша коли математична модель описує період умовно постійної швидкості висушування і пов'язана з винесенням вільної вологи з поверхні виробу до досягнення нею повітряно-сухого рівноважсного стану. Друга коли описує період з спадною швидкістю сушіння, коли фронт випаровування вологи проникає всередину продукту. Записані диференціальні рівняння переносу для теплоносія при обтіканні поверхні виробу потоком в граничному шарі при розгляді градієнтів швидкості, температури і вмісту вологи. Розглянутий період спадної швидкості сушіння, коли фронт випаровування проникає всередину матеріалу. Були проведені експериментальні дослідження і після їх обробки отримали деякі критеріальні рівняння для опису процесу сушіння м'ясних виробів. На підставі проведеного аналізу перепадів вологості в матеріалі встановлено, шчо проведення процесу сушіння при більш високих температурах характеризується меншими значеннями перепадів вологовмісту, ніж при нижчих.
\end{abstract}

Ключові слова: модель, сушіння, тепломасоперенос, конвективний, м’ясні, вироби

\section{MODEL OF WARM MASS TRANSFER PROCESS FOR CONVECTIONAL DRYING MEAT PRODUCTS}

Oshchypok I.M. Dr. Sciences, Professor

Lviv trade and economic University, Lviv

\begin{abstract}
The article considers the model. the solution of the actual problem in the field of technics and technology of drying meat products, which is associated with the factors of studying and deepening the idea of the physical nature and the pattern of energy transfer and substance transfer under different drying methods for the creation of scientifically substantiated method of technical and economic assessment drying facilities for drying meat products .. The mathematical modeling of the process of drying the surface moisture from the products after the appropriate technological treatment is relevant, since it defines the terms of long storage tion. The problem of evaporation of the liquid from the surface of the capillary-porous body is considered in three aspects, and the general task of modeling the processes of heat and mass transfer with convective drying of meat products with additional inflammation of infrared energy is considered in two components. The first one when the mathematical model describes the period of a conditionally constant drying rate and is associated with the removal of free moisture from the product surface until it reaches the air-dry equilibrium state. The second one describes a period with a decreasing drying rate, when the moisture evaporation front enters the product. The differential transport equations for the coolant are recorded at the flow of the surface of the product by flow in the boundary layer when considering the gradients of velocity, temperature and moisture content. Considered the period of decreasing drying rate, when the front of evaporation penetrates into the material. Experimental studies were carried out and after their processing, some criterion equations were obtained for describing the process of drying meat products. Based on the analysis of moisture variations in the material, it was established that the process of drying at higher temperatures is characterized by lower values of moisture-city fluctuations than at lower temperatures.
\end{abstract}

Keywords: model, drying, warm mass transfer, convective, meat products

Постановка проблеми в загальному вигляді та зв'язок із найважливішими науковими чи практичними завданнями. Одним з розповсюджених методів збереження й переробки сільськогосподарської сировини є сушіння. У зв'язку з цим виникає необхідність удосконалення способів сушіння м'ясних виробів, що забезпечують високу якість готового продукту, створення умов для більш повної переробки сировини, зме- 
ншення втрат, автоматизацію, механізацію й значну інтенсифікацію цього процесу, а також зниження питомих енерговитрат. Рішення актуальних завдань у сфері техніки й технології сушіння безпосередньо пов'язують з наступними факторами: вивченням і поглибленням уяви про фізичну сутність і закономірність переносу енергії й речовини при різних методах сушіння; подальшим вивченням властивостей матеріалу, як об'єкта сушіння; застосуванням новітніх фізико-хімічних методів дослідження, обгрунтуванням методів управління механізмом переносу вологи всередині матеріалу у процесах сушіння; створенням науково обгрунтованої методики техніко-економічної оцінки сушильних установок.

Аналіз останніх досліджень і публікацій. Сушіння вологих матеріалів - це складний термо- і масодифузійний процес. Для складних багатокомпонентних систем, якими є м'ясні вироби, процес сушіння представляється у вигляді двох складових: теплофізичної й технологічної. Якщо теплофізичний процес сушіння визначає «чисте» переміщення тепла й вологи крізь товщу продукту, то технологічний являє собою сукупність процесів переміщення вологи й тепла, що супроводжуються хімічними, біохімічними й структурномеханічними змінами. Дослідження на які опирається автор викладені в роботах [1-6].

Постановка завдання. Питання математичного моделювання процесу сушіння поверхневої вологи 3 виробів після відповідної технологічної обробки є актуальним, і визначає терміни тривалого зберігання. Загальну задачу моделювання процесів тепломасопереносу при конвективному сушінні продуктів 3 додатковим підведенням інфрачервоної (ІЧ) енергії, розглянемо в двох складових. Перша коли математична модель описує період умовно постійної швидкості висушування і пов'язана з винесенням вільної вологи 3 поверхні виробу до досягнення нею повітряно-сухого рівноважного стану. Друга коли описує період з спадною швидкістю сушіння, коли фронт випаровування вологи проникає всередину продукту.

Виклад основного матеріалу дослідження. Поверхня тіла покрита суцільним шаром вологи (зовнішня задача). В цьому випадку процес масопереносу аналогічний випаровуванню з вільної поверхні рідини. При додатковому підведенні ІЧ-енергії швидкість масопереносу не залишається постійною, як в класичному випадку, а зростає пропорційно величині поглинання потужності ІЧ-випромінювання. У зв'язку з цим, даний період будемо розглядати як період умовно постійної швидкості висушування. Випаровування в окремих місцях при якому процес масопереносу відбувається частково, але з вільної змоченої поверхні, а частково 3 висушеної, коли рівень рідини в капілярах збігається з видимою геометричною поверхнею виробу. Поверхня випаровування переміщається всередину, в глибину матеріалу з утворенням прошарку, що представляє собою додатковий опір переносу теплоти і речовини з середини продукту (внутрішня задача).Такий підхід найбільш прийнятний, так як в масі виробу, під час обробки мають місце ділянки, які обробляють в режимі як першого, так і другого періоду одночасно.

В якості моделі одиничного виробу приймемо площину діаметром D i товщиною $2 \mathrm{R}$. Вісь X орієнтована уздовж поверхні, a Z перпендикулярна поверхні виробу. Початком координатної системи вибрано вісь симетрії поперечного перерізу виробу. В період умовно постійної швидкості сушіння вологий матеріал-виріб містить як зв'язану (гігроскопічну), так і вільну вологу і тому буде вважатись мокрим або сирим матеріалом. В цьому випадку завдання сушіння зводиться до зовнішньої задачі - тобто до видалення вільної вологи. При обтіканні поверхні виробу потоком теплоносія, в граничному шарі виникають градієнти швидкості, температури і вмісту вологи. Диференціальні рівняння переносу для теплоносія можуть бути записані в наступному вигляді.

Рівняння переносу маси:

$$
\frac{\partial U_{T}}{\partial \tau}+V_{x} \frac{\partial V_{T}}{\partial x}+V_{z} \frac{\partial V_{T}}{\partial z}=a_{m}^{T}\left(\frac{\partial^{2} U_{T}}{\partial z^{2}}+\frac{\partial^{2} U_{T}}{\partial x^{2}}\right)+a_{m}^{T} b_{T}\left(\frac{\partial^{2} t_{T}}{\partial z^{2}}+\frac{\partial^{2} t_{T}}{\partial x^{2}}\right)
$$

$U_{T}=\frac{G_{a s}}{G_{\varepsilon}}-\quad$ питомий вміст вологи теплоносія;

$\mathrm{V}_{\mathrm{x}}$ - поздовжня швидкість обтікання виробу, м/с;

$\mathrm{x}$ - поздовжня координата, м;

z - поперечна координата, нормальна до поверхні виробу, м;

$\mathrm{V}_{\mathrm{z}}$ - компонента швидкості, нормальна до поверхні виробу, м/с;

m - коефіцієнт масопровідності (дифузії), $\mathrm{m}^{2} / \mathrm{c}$;

$\mathrm{dT}$ - термоградієнтний коефіцієнт, $\mathrm{K}^{-1}$;

$\mathrm{t}_{\mathrm{T}}$ - температура теплоносія, $\mathrm{K}$;

$\mathrm{G}_{\text {вл }}, \mathrm{G}_{\mathrm{c}}$ - маса вологи і сухого повітря, кг.

Рівняння переносу теплоти:

$$
\frac{\partial t_{T}}{\partial \tau}+V_{x} \frac{\partial t_{T}}{\partial x}+V_{z} \frac{\partial t_{T}}{\partial z}=a_{T}\left(\frac{\partial^{2} t_{T}}{\partial z^{2}}+\frac{\partial^{2} t_{T}}{\partial x^{2}}\right)+\frac{\varepsilon v_{Y}}{c_{\tau}} \frac{\partial v_{T}}{\partial \tau}+\frac{q}{c_{\tau} \rho_{T}}
$$

де $\alpha_{\mathrm{T}}$ - коефіцієнт температуропровідності, $\mathrm{m}^{2} / \mathrm{c}$;

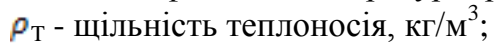

Наукові праці, Том 83, випуск 1 Scientific Works, Volume 83, Issue 1 
$\mathrm{c}_{\mathrm{T}}$ - питома теплоємність, Дж/кг К;

q - об'ємна потужність ІЧ випромінювання, Вт/м²;

r - питома теплота випаровування води, Дж/кг;

$\varepsilon$ - коефіцієнт фазового переходу.

Слід зазначити, що в роботі [5] показано досить слабкий вплив фактору поперечного потоку маси на процеси тепло- і масообміну в процесах випаровування. Таким чином, в рівняннях (1) і (2) можна прийняти:

$$
V_{z} \frac{\partial U_{T}}{\partial z}=0 ; \quad V_{z} \frac{\partial t_{T}}{\partial z}=0 .
$$

У період умовно постійної швидкості сушіння (зовнішня задача) можуть бути записані рівняння збереження енергії і маси для висушуваного об'єкту.

Щільність потоку маси визначається механізмом переміщення вологи всередині матеріалу у вигляді пари або рідини (вологопровідність, термовологопровідність, бародифузія) і механізмом переміщення вологи 3 поверхні матеріалу в навколишнє середовище через приграничний шар при природній або вимушеній конвекції, а так само енергетикою випаровування (питома теплота випаровування, структура, розмір і форма капілярів, енергія зв'язку вологи).

Загальний вираз для щільності потоку вологи в капілярно-пористому тілі (в напрямку осі Z) записується у вигляді співвідношення:

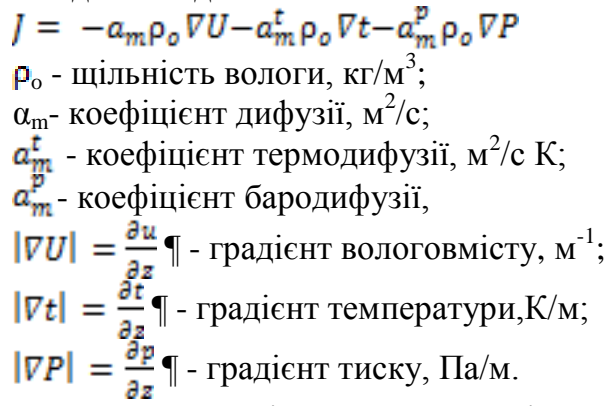

При цьому необхідно мати на увазі наступні обставини:

Так, як температура теплоносія в реальних умовах становить величину меншу за $80^{\circ} \mathrm{C}$, то явищем бародифузії нехтуємо.

За результатами експериментальних досліджень зміна температури поверхні висушуваного зразка становить близько $7{ }^{\circ} \mathrm{C}$, у зв'язку з чим компоненту термовологопровідності можна також опустити. У такому випадку рівняння збереження маси для зразка може бути записане у формі рівняння (1), а рівняння збереження енергії для висушуваного плоского двовимірного об'єкта, в умовах нехтування термічним опором тонкої плівки вологи, може бути записане в класичному вигляді [5]:

де $\rho$ - щільність матеріалу виробу, кг/м $\mathrm{m}^{3}$

$$
\frac{\partial t}{\partial \tau}=a\left(\frac{\partial^{2} t}{\partial z^{2}}+\frac{\partial^{2} t}{\partial x^{2}}\right)+\frac{\partial r}{c} \frac{\partial U}{\partial \tau}+\frac{q}{c_{p}}
$$

Для розв'язання рівнянь (1), (2), (3) тепломасопереносу в першому періоді сушіння необхідно сформувати умови однозначності - крайові задачі.

Для нашого випадку, з урахуванням фазового переходу при випаровуванні води з вільної поверхні, граничні умови третього роду для рівнянь (1) і (2) приймуть вигляд:

$$
\begin{aligned}
& \lambda_{m} \cdot \delta_{T}\left(\frac{\partial t}{\partial z}\right)_{i}+\lambda_{m}\left(\frac{\partial U}{\partial z}\right)_{i}=\beta \rho_{i}\left(U_{n}-U_{T}\right) \\
& -\lambda\left(\frac{\partial t}{\partial z}\right)_{n}+a\left(t_{T}-t_{n}\right)=\beta_{r} \rho_{i} \varepsilon\left(U_{n}-U_{T}\right)
\end{aligned}
$$

де $\lambda\left(\frac{\partial t}{\partial z}\right)_{n}$ - потік теплоти за рахунок теплопровідності;

$a\left(t_{T}-t_{\mathrm{n}}\right)$ - потік теплоти за рахунок теплообміну;

$\beta_{r} \rho_{i} \mathcal{E}\left(U_{n}-U_{T}\right)$ - потік теплоти за рахунок випаровування;

$\beta p_{i}\left(U_{n}-U_{T}\right)$ - потік маси випаровуваної вологи;

$\lambda_{m} \times \delta_{T}\left(\frac{\partial t}{\partial z}\right)_{i}$ - потік маси, що випаровується за рахунок термовологопровідності;

$\lambda_{m}\left(\frac{\partial v}{\partial z}\right)_{i}$ ๆ - потік маси, що випаровується за рахунок вологопровідності (діфузії);

$\lambda$ - коефіцієнт теплопровідності, Вт/м К;

a - коефіцієнт тепловіддачі, Вт/м² К;

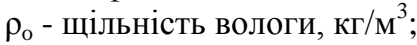

$\beta$ - коефіцієнт масовіддачі, м/с;

$\lambda_{\mathrm{m}}$ - коефіцієнт масопровідності,

Початкові умови записуються в наступному вигляді: 
$\mathrm{t}(\mathrm{R}, 0)=\mathrm{t}_{\mathrm{n}}=$ const; $\mathrm{U}(\mathrm{R} ; 0)=\mathrm{U}_{\mathrm{T}}$,

тут: $\pm \mathrm{R}$ - координати $\mathrm{Z}$ для верхньої і нижньої поверхні виробу при товщині виробу $2 \mathrm{R}$;

п - індекс для поверхні виробу.

Слід зазначити, що граничні умови 3 роду для рівняння (3) при зазначеному способі сушіння виробу записуються в формі рівняння (5).

Початкові умови записуються в наступному вигляді:

$$
t(R, 0)=t_{n}=\text { const } ; \quad U(R, 0)=U_{r}
$$

де $\mathrm{U}_{\mathrm{r}}$ - гігроскопічний вологовміст матеріалу виробу.

Необхідність розгляду періоду спадної швидкості фази сушіння розглядуваного процесу обумовлена, як зазначалось раніше, наявністю об'єктів, які знаходяться в стадії не тільки першого, але й другого періоду спадної швидкості сушіння, коли фронт випаровування проник всередину матеріалу по координаті z.

У другому періоді сушіння видаляється гігроскопічна (зв'язана) волога, з огляду на те, що вся вільна волога 3 поверхні матеріалу видалена. Таким чином, в умовах нехтування бародифузії, рушійною силою процесу масопереносу $є$ градієнт вмісту вологи і температури.

В цьому випадку спільну систему рівнянь тепло- і масопереносу можна записати в наступному вигляді:

$$
\begin{aligned}
& \frac{\partial U}{\partial \tau}=a_{m}\left(\frac{\partial^{2} U}{\partial x^{2}}+\frac{\partial^{2} U}{\partial x^{2}}\right)+a_{m} \delta_{i}\left(\frac{\partial^{2} t}{\partial z^{2}}+\frac{\partial^{2} t}{\partial x^{2}}\right) . \\
& c p \frac{\partial t}{\partial \tau}=\lambda\left(\frac{\partial^{2}}{\partial x^{2}}+\frac{\partial^{2} t}{\partial x^{2}}\right)+\varepsilon r p \frac{\partial U}{\partial \tau}+q
\end{aligned}
$$

де: $\rho$ - щільність матеріалу виробу, кг/м³

$\delta_{\mathrm{i}}$ - термоградієнтний коефіцієнт для виробу, $1 /$ К.

$\mathrm{y}$ початковий момент часу температуру $\mathrm{t}_{\mathrm{H}}$ i вологовміст $\mathrm{U}_{\mathrm{o}}(\mathrm{t})$ виробу приймаємо постійними:

$$
\begin{array}{r}
\mathrm{t}(\mathrm{z}, 0)=\mathrm{t}_{\mathrm{n}}=\text { const, } \\
\mathrm{U}(\mathrm{z} ; 0)=\mathrm{U}_{\mathrm{o}}(\mathrm{t})=\text { const, }
\end{array}
$$

При цьому слід мати на увазі, що $\mathrm{U}_{\mathrm{o}}(\mathrm{t})$ - гігроскопічний вологовміст виробу, який установився до моменту закінчення сушіння вільної вологи $з$ поверхні виробу.

Граничні умови можуть бути записані у наступному вигляді:

$$
\begin{gathered}
\frac{\partial t(0, \tau)}{\partial z}=0 ; \quad \frac{\partial U(0, \tau)}{\partial z}=0 \\
t( \pm R, \tau)=t_{0}+a(v) e^{\frac{-b(v)}{\tau}+c(\varphi) ;} \frac{-m[(\varphi)}{\tau} \\
a_{m} P_{0}\left(\frac{\partial v}{\partial z}\right) z= \pm R+a_{m} P_{0} \mathrm{~b}\left(\frac{\partial t}{\partial z}\right) z= \pm R+\beta \rho_{0} \varepsilon\left(U_{n}-U_{T}\right)=0
\end{gathered}
$$

де $a_{m} \mathrm{Po}_{0}\left(\frac{\partial v}{\partial z}\right)_{z= \pm R}$ - дифузійний потік маси з поверхні виробу;

$\mathrm{Z}= \pm \mathrm{R}$ - потік маси за рахунок термовологопровідності;

$\beta \rho_{0} \varepsilon\left(U_{n}-U_{T}\right)$ - потік маси за рахунок масообміну;

$\varphi$ - відносна вологість теплоносія;

a (v), b (v), c ( $\varphi), \mathrm{m}(\varphi)$ - емпіричні коефіцієнти.

Поставлена задача (1) - (13) не може бути вирішена аналітично без істотного спрощення в зв'язку з математичними труднощами, обумовленими як не лінійністю, так і змінністю коефіцієнтів переносу. Тому для наступного етапу реалізації шуканого рішення доцільно вибрати перехід до критеріальних рівнянь [6]. У даному випадку при переході до рівнянь подібності розглянутий період умовно постійної швидкості висушування.

Перетворюючи отримані диференціальні рівняння (1), (2) і крайові умови (4), (5) до безрозмірного вигляду і приймаючи в якості визначального критерію Нусельта і Нуссельта дифузійного, зв'язана система рівнянь подібності спільного тепломасопереносу для моменту часу, відповідного максимальній різниці рушійних потенціалів, перетворюється до наступного узагальненого вигляду:

де $\operatorname{Re}$ - критерій Рейнольдса,

$$
\left\{\begin{array}{c}
N u_{d}=f_{1}\left(\text { Pn Ko Gu } D^{*} / H_{s} D^{*} / L\right. \\
N u=f_{2}\left(\operatorname{Re} \operatorname{Pr} \operatorname{Pn} \text { Ko Gu } D^{*} / H_{s} D^{*} / L\right.
\end{array}\right.
$$

$\operatorname{Pr}$ - критерій Прандтля.

Pn - критерій Поснова,

Ко - критерій Коссовіча, 


\footnotetext{
Ро - критерій Померанцева,

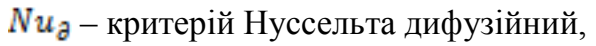

$\mathrm{Nu}$ - критерій Нуссельта

$\mathrm{Gu}$ - критерій Гухмана,

$\mathrm{D} * / \mathrm{H}, \mathrm{D} * / \mathrm{L}-$ геометричні симплекси,

$\mathrm{D} *$ - еквівалентний діаметр насадки,

$\mathrm{L}$ - довжина обтікання виробу,

H - товщина шару виробу в насадці.
}

Визначення конкретних значень параметрів функцій $\mathrm{f}_{1} \mathrm{i}_{2}$ вимагає здійснення серії експериментів. Такі експериментальні дослідження були проведені і їх обробка дозволила отримати наступні критеріальні рівняння.

Середнє значення безрозмірного коефіцієнта масообміну для одиничного виробу в безмежному середовищі визначається співвідношенням:

$$
\begin{aligned}
N u & =340 \text { Po0,709Re } 0,512 G u 0,531 \\
\text { Для невпорядкованої насадки: } & N u=590 P \text { o } 0,716 \operatorname{Re} 0,519 G u 0,539\left(D^{*} / H\right) 0,53\left(D^{*} / L\right) 0,361
\end{aligned}
$$

Відсутність в отриманих рівняннях критеріїв Кo, Pn i Pr обумовлено їх виродженням у зв'язку з фізичною та формальною автомодельністю процесу сушіння щодо зазначених чисел подібності.

Висновки. Наведені рівняння описують експериментальні дані з похибкою дещо вищою як прийнята в наукових дослідженнях: 10 \% в діапазоні температур теплоносія (293-373) К, швидкостей потоку $(1,0-3,9)$ м/с, потужності ІЧ-випромінювання (10-720) Вт/м².

У зв'язку з цим, на першому етапі вологовидалення на кінетику процесу впливає як зовнішня, так і внутрішня дифузія, тому збільшення температури сушіння впливає на перепади вологості в матеріалі, як через коефіцієнт масопровідності, так і через коефіцієнт масовіддачі. На заключних етапах сушіння роль зовнішньодифузійного опору мала, і в тілі формуються градієнти, величина яких визначається при інших рівних умовах тільки коефіцієнтом масопровідності. У цих умовах збільшення температури, викликаючи значний приріст коефіцієнту масопровідності, приводить до закономірного зменшення градієнтів вологовмісту в матеріалі.

На підставі проведеного аналізу перепадів вологості в матеріалі встановлено, що проведення процесу сушіння при більш високих температурах характеризується меншими значеннями перепадів вологовмісту, ніж при нижчих. Можна також припустити, що менші перепади вологовмісту будуть викликати значно менші механічні напруження в виробі. 3 точки зору збереження технологічних властивостей продукту можна рекомендувати технологічний режим сушіння в температурному інтервалі $80 \div 95{ }^{\circ} \mathrm{C}$

При подальших дослідженнях процесів сушіння м'ясних виробів слід уточнити параметри моделі для вибраних сушильних апаратів і описати конкретні геометричні виміри висушуваних виробів особливо слід звертати увагу на сировину з якої виготовляється продукт: яловичина, свинини, птиця.

\section{References}

1. Burdo, O. G. (2016). The Nanotechnological Innovation in Food Industry Int. J. Eng. Res. Appl. (IJERA), ISSN 2248-9622, www.ijera.com.. 6(3),144-150.

2. Burdo, O., Zykov, A., Terziev, S., Ruzhitskaya, N. (2016) The technologies of targeted energy supply in food industry. MOTROL. Com. Mot. Energ. Agric. Lublin,. 18(8). 7 - 14.

3. Dakuorta, R.B. (1980). Voda v pishchevykh produktakh.Pod redaktsiyey. Perevod s angl. M.: Pishchevaya promyshlennost', 376 .

4. Ginzburg, A. S. (1980) Teplofizicheskiye kharakteristiki pishchevykh produktov. Spravochnik. Izdaniye vtoroye, dopolnennoye i pererabotannoye. Pishchevaya promyshlennost'. Moskva. 288.

5. Oshchypok, I. M (2014) Enerhozberezhennya u teplovykh merezhakh hotel'no-restorannykh kompleksiv za rakhunok zminy parametriv teplonosiya. Nauk.pratsi ONAKHT, Odesa., 45(2). 185-190.

6. Snyezhkin, Yu.F., Shapar, R.O., Sorokova, N.M., Husarova, O.V. (2015). Rozrobka tekhnolohiyi vyrobnytstva novykh form sushenykh produktiv // Promyshlennaya teplotekhnyka, h. Kyev,. 37(6). 29 -37.

Отримано в редакцію 04.04.2019

Прийнято до друку 22.06.2019
Received 04.04.2019

Approved 22.06.2019 